\title{
Development, structure and composition of land-fast sea ice in the northern Baltic Sea
}

\author{
Mats A. GRANSKOG,${ }^{1 *}$ Tõnd A. MARTMA, ${ }^{2}$ Rein A. VAIKMÄE ${ }^{2}$ \\ ${ }^{1}$ Division of Geophysics, Department of Physical Sciences, University of Helsinki, FIN-00014 Helsinki, Finland \\ E-mail:mats@iki.fi \\ ${ }^{2}$ Institute of Geology, Tallinn Technical University, 7 Estonia Avenue, EE-10143 Tallinn, Estonia
}

\begin{abstract}
The structural and stable-oxygen-isotopic properties of sea-ice samples collected on land-fast sea ice in the northern Baltic Sea, at $60.2-65.7^{\circ} \mathrm{N}, 21.3-26.9^{\circ} \mathrm{E}$, were used to estimate the contribution of snow ice to the total sea-ice thickness, and the fraction of snow in the snow-ice layers and in the total sea-ice thickness. The textural analysis of the sea-ice cores revealed a general structure of a granular surface layer and a columnar basal layer. Using different isotopic criteria to distinguish snow-ice layers, we estimate that snow-ice layers contributed on average $24-32 \%$ of the total ice thickness in the study region. Transition ice (intermediate granular-columnar ice) also contributed significantly to the total ice thickness. The snow in the snow-ice layers contributed on average $18-21 \%$ of the total sea-ice thickness (by mass), a significant contribution when compared to other regions with sea-ice cover. The methods used could be improved to give more accurate estimates, especially by improving knowledge of the temporal variability of the isotopic properties of the snow incorporated into the sea-ice cover. However, our results can be regarded as plausible estimates for the contribution of snow ice and snow to sea-ice growth in the study area.
\end{abstract}

\section{INTRODUGTION}

The Baltic Sea is characterized as a brackish water basin, with only a narrow connection to the world ocean through the shallow Danish straits. Sea ice occurs annually; however, the interannual variability in ice cover is large (e.g. Seinä and Peltola, 1991). During mild winters, only coastal regions and the Bothnian Bay are ice-covered (Fig. 1), whereas during severe winters almost the whole sea is ice-covered. The ice season lasts for 5-7 months in the northernmost parts and decreases in duration towards the south (e.g. Seinä and Peltola, 1991). The maximum ice extent occurs in midFebruary to mid-March. The land-fast ice cover usually extends to the outer skerries, where the water depth is 5$15 \mathrm{~m}$. Further offshore the ice cover is highly dynamic (e.g. Leppäranta, 1981). Fast ice grows $20-100 \mathrm{~cm}$ thick, depending on the winter and location; the maximum observed level ice thickness is $122 \mathrm{~cm}$ (Seinä and Peltola, 1991). The salinity of the surface water is 3-7 PSU (practical salinity units) on the Finnish coast, while the sea-ice salinity is generally $<2$ PSU (e.g. Palosuo, 1963). Observations of the stableoxygen-isotopic properties $\left(\delta^{18} \mathrm{O}\right)$ in the northern Baltic Sea, especially the Gulf of Bothnia, are virtually non-existent. Punning and others (1991) presented $\delta^{18} \mathrm{O}$ values of -6 to $-8 \%$ o for water salinities of $5-15 \%$. Observations show that the relationship between salinity and $\delta^{18} \mathrm{O}$ is close to linear

* Present address: Arctic Centre, University of Lapland, Box 122, FIN-96101 Rovaniemi, Finland.
(Fröhlich and others, 1988; Punning and others, 1991), with some seasonal deviations mainly due to evaporation.

As Weeks and others (1990) noted, one might suppose that the characteristics of sea ice in a restricted and economically important water such as the Bothnian Bay would have been extensively over-studied, but this is not the case. This applies to the whole Baltic Sea as well. Studies on sea ice in the Baltic Sea to date have mainly focused on large-scale problems, such as ice dynamics and climatology (e.g. Leppäranta, 1981; Haapala and Leppäranta, 1996, 1997). However, a thorough understanding of the role of sea ice in the Baltic Sea, whether from an oceanographic, climatological or biological perspective, requires quantitative estimates of different ice-growth processes.

The crystal structure of sea ice in the Baltic Sea shows large variability (Palosuo, 1961, 1963; Omstedt, 1985; Fransson and others, 1990; Weeks and others, 1990), although these studies have often been restricted to certain geographical areas. In pack ice, dynamic thickening is important (e.g. rafting and ridging plays an important role). Weeks and others (1990) found pack ice to be composed of up to $80 \%$ granular ice. In coastal areas the ice cover is more static, and often the ice sheet consists of two distinct layers: an upper granular layer (partly snow ice) and a lower columnar layer (see, e.g., Palosuo, 1963).

Snow-ice formation is a widely occurring process in Antarctic waters (e.g. Lange and others, 1990; Eicken and others, 1994; Jeffries and others, 1994, 1997; Kawamura and others, 1997; Eicken, 1998; Haas and others, 2001), and some observations on its importance have also been reported from the Baltic Sea (Palosuo, 1963; Kawamura and others, 2001). Snow ice forms when the snow load on the ice depresses the ice sur- 


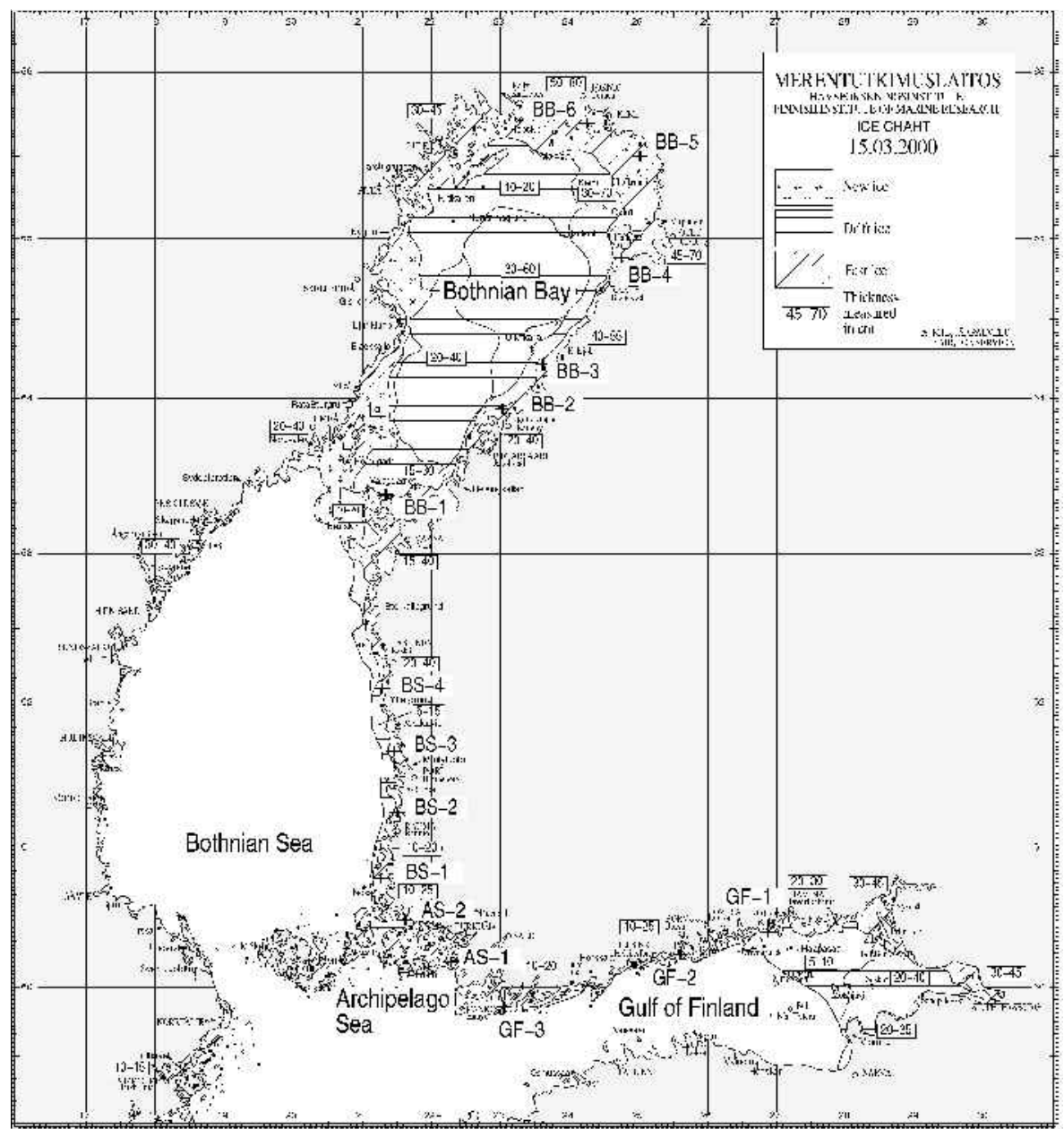

Fig. 1. Map of the northern Baltic Sea showing the location of the sampling sites in March 2000 and the ice conditions on 15 March (ice chart of the Finnish Institute of Marine Research Ice Service). In the labels for the sampling sites, GF, AS, BS and $B B$ refer to the Gulf of Finland, the Archipelago Sea, the Bothnian Sea and the Bothnian Bay, respectively.

face below sea level (i.e. sea ice has a negative freeboard), so the sea water can potentially flood onto the ice and produce a layer composed of a mixture of snow and sea water (slush). This slush can freeze, and form snow ice on top of the existing sea-ice cover (e.g. Haas and others, 2001). Superimposed ice is formed when snow meltwater refreezes (e.g. Kawamura and others, 1997). Recently snow-ice formation has been recognized to have an impact on several factors (e.g. it is an effective way of sea-ice thickening since the freezing interface is closer to the atmosphere (the heat sink) than in ice growth at the ice-water interface (e.g. Maksym and Jeffries, 2000)). Furthermore the flooding and subsequent snow-ice formation processes may be important for nutrient replenishment for seaice algae (Fritsen and others, 1994), and slush layers can be an important habitat for (ice) algae (Haas and others, 2001).

Very little quantitative information is available on the amounts of snow ice and frazil ice that make up the granular layer in the Baltic Sea. Observations by Palosuo (1963) show large spatial and interannual variability in the amount of snow (white ice) incorporated into the ice cover. According to studies on land-fast sea ice in the Gulf of Finland, granular ice may contribute up to $42 \%$ of the total ice thickness (Kawamura and others, 2001). Data on the stable-isotopic composition of Baltic Sea ice are limited to those obtained from one site on the coast of the Gulf of Finland (Kawamura and others, 2001). These observations indicated a significant contribution from snow, the snow fraction (by mass) being up to $26 \%$ during the ice season.
The main motivation for the use of oxygen isotopes in sea-ice studies is that they provide information on the role of snow in sea-ice processes, such as flooding, snow-ice formation and meltwater transport (e.g. Lange and others, 1990; Eicken and others, 2002). This study concerns detailed observations of sea-ice properties in the Baltic Sea during one particular ice season, winter 1999/2000. Results from observations made on land-fast sea ice along the Finnish coast are presented. The objective was to study the structural properties and stable-oxygen-isotopic composition $\left(\delta^{18} \mathrm{O}\right)$, and to understand the key growth processes of land-fast sea ice along the whole coast. The contribution of snow to ice formation was of special interest, since earlier studies have shown that it is potentially important for the thickening of the sea-ice cover, but no quantitative estimates have been presented for the Baltic Sea previously, except for one site in the Gulf of Finland (Kawamura and others, 2001).

\section{STUDY AREA AND METHODS}

Sea-ice samples were collected at 15 sites along the Finnish coast of the Baltic Sea (Fig. 1), at $60.2-65.7^{\circ} \mathrm{N}, 21.3-26.9^{\circ} \mathrm{E}$, in March and April 2000. Winter 1999/2000 was relatively mild, with ice covering only the Bothnian Bay and some coastal areas further south (Fig. 1). The maximum ice extent was reached in late February, when $23 \%$ of the Baltic Sea was ice-covered, compared to a longer-term average of 
Table 1. Description of sampling sites along the Finnish coast of the Baltic Sea. The snow depth is the measured snow depth (or range observed) on the ice at the sampling site

\begin{tabular}{lccc}
\hline Site & Ice & Snow & Comments \\
& & Cocation & \\
& thickness & depth &
\end{tabular}

$\mathrm{cm} \quad \mathrm{cm}$

\begin{tabular}{llccl}
\hline GF-1 & $60.40^{\circ} \mathrm{N}, 26.86^{\circ} \mathrm{E}$ & 15 & 0 & No snow on ice \\
GF-2 & $60.23^{\circ} \mathrm{N}, 25.60^{\circ} \mathrm{E}$ & 21 & $0-2$ & No snow on ice \\
GF-3 & $59.87^{\circ} \mathrm{N}, 23.05^{\circ} \mathrm{E}$ & 25 & $2-5$ & \\
AS-1 & $60.18^{\circ} \mathrm{N}, 22.83^{\circ} \mathrm{E}$ & 17 & $0-1$ & No snow on ice \\
AS-2 & $60.48^{\circ} \mathrm{N}, 21.61^{\circ} \mathrm{E}$ & 19 & $2-5$ & \\
BS-1 & $60.79^{\circ} \mathrm{N}, 21.27^{\circ} \mathrm{E}$ & 21 & $2-5$ & Hard refrozen snow \\
BS-2 & $61.25^{\circ} \mathrm{N}, 21.51^{\circ} \mathrm{E}$ & 31 & $5-10$ & Sheltered embayment \\
BS-3 & $61.67^{\circ} \mathrm{N}, 21.42^{\circ} \mathrm{E}$ & 26 & $0-10$ & Patchy snow \\
BS-4 & $62.10^{\circ} \mathrm{N}, 21.29^{\circ} \mathrm{E}$ & 36 & $5-10$ & Wet snow \\
BB-1 & $63.38^{\circ} \mathrm{N}, 21.33^{\circ} \mathrm{E}$ & 40 & $0-10$ & Patchy wet snow \\
BB-2 & $63.93^{\circ} \mathrm{N}, 23.05^{\circ} \mathrm{E}$ & 65 & $15-20$ & \\
BB-3 & $64.21^{\circ} \mathrm{N}, 23.62^{\circ} \mathrm{E}$ & 59 & $5-15$ & Hard refrozen snow \\
BB-4 & $64.88^{\circ} \mathrm{N}, 24.76^{\circ} \mathrm{E}$ & 61 & $5-25$ & Hard packed snow \\
BB-5 & $65.54^{\circ} \mathrm{N}, 25.08^{\circ} \mathrm{E}$ & 66 & $20-25$ & Hard packed snow \\
BB-6 & $65.74^{\circ} \mathrm{N}, 24.25^{\circ} \mathrm{E}$ & 72 & $25-40$ & Hard packed snow \\
& & & & \\
\hline
\end{tabular}

about $45 \%$. The ice thickness was also less than average: the thickness of the sampled ice cores varied between 17 and $72 \mathrm{~cm}$, with a mean thickness of $38 \mathrm{~cm}$ (Table 1). Snow thickness at the sites varied between 0 and $40 \mathrm{~cm}$ (Table 1).

An ice core $13 \mathrm{~cm}$ in diameter was taken at each site for determination of salinity, crystal structure and stable- oxygen-isotopic properties $\left(\delta^{18} \mathrm{O}\right)$. In addition, snow and surface water samples were collected whenever possible, and conductivity and temperature profiles of the water column were also measured frequently. Directly after retrieval, the cores were put in plastic tubing and kept in a freezer $\left(<-20^{\circ} \mathrm{C}\right)$ prior to analysis.

In the cold room (at -15 to $-20^{\circ} \mathrm{G}$ ) at the Technical Research Centre of Finland, Espoo, and the University of Oulu, Finland, each core was split lengthwise to obtain a $1 \mathrm{~cm}$ thick section, which was cut into $10-20 \mathrm{~cm}$ long vertical sections. These were attached to glass plates, planed to about $1 \mathrm{~mm}$ thickness, and then examined between crossed polarizers to identify the crystal structure. Hereafter the remainder of the core was divided into sections, usually $1-10 \mathrm{~cm}$ long, along structural boundaries.

A 100-200 mL sample of each structural section was taken from the central part of the core and put into a zip-lock polyethylene bag. The pieces were melted at room temperature, and, immediately after melting, $40 \mathrm{~mL}$ bottles were filled completely and closed tightly. The water samples were shipped to the Institute of Geology, Tallinn, where $\delta^{18} \mathrm{O}$ was determined using a Finnigan-MAT Delta-E mass spectrometer (FinniganMAT, Bremen, Germany). Results are measured against laboratory internal standard water, which has been calibrated on the V-SMOW/SLAP scale using the international reference materials V-SMOW (Vienna Standard Mean Ocean Water) and SLAP (Standard Light Antarctic Precipitation) from the International Atomic Energy Agency (IAEA), Vienna, Austria. Reproducibility of replicate analyses is generally better than $\pm 0.1 \%$. Salinity was determined from the same melted
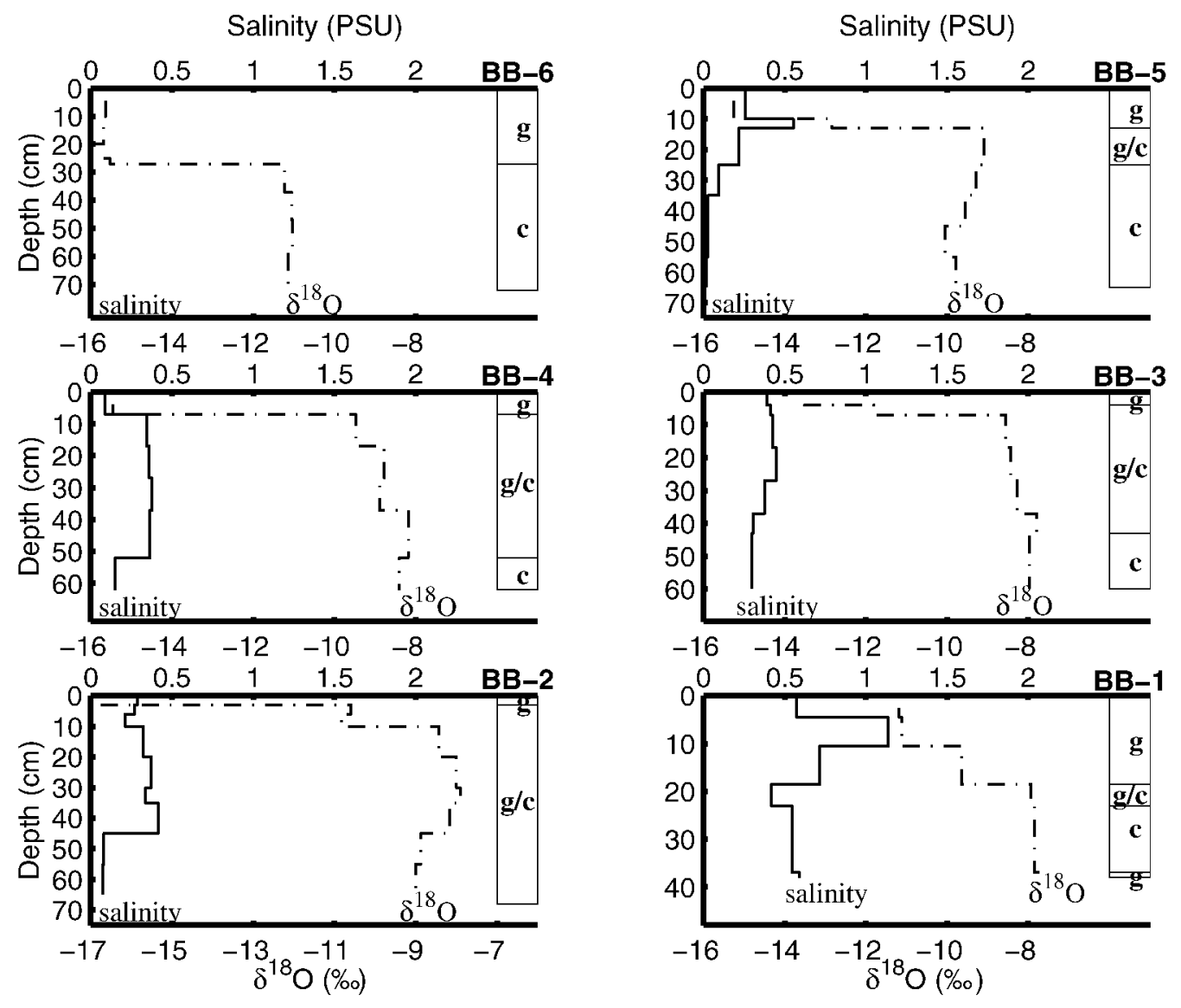

Fig. 2. Structural properties and vertical profiles of salinity and $\delta^{18} \mathrm{O}$ for ice cores from the Bothnian Bay. The ice cores were divided into granular ice ( $\mathrm{g}$ ), a mixture of granular and columnar ice ( $\mathrm{g} / \mathrm{c})$, termed transition ice, and columnar ice (c). The vertical scale depends on the individual ice-core length. 
Salinity (PSU)

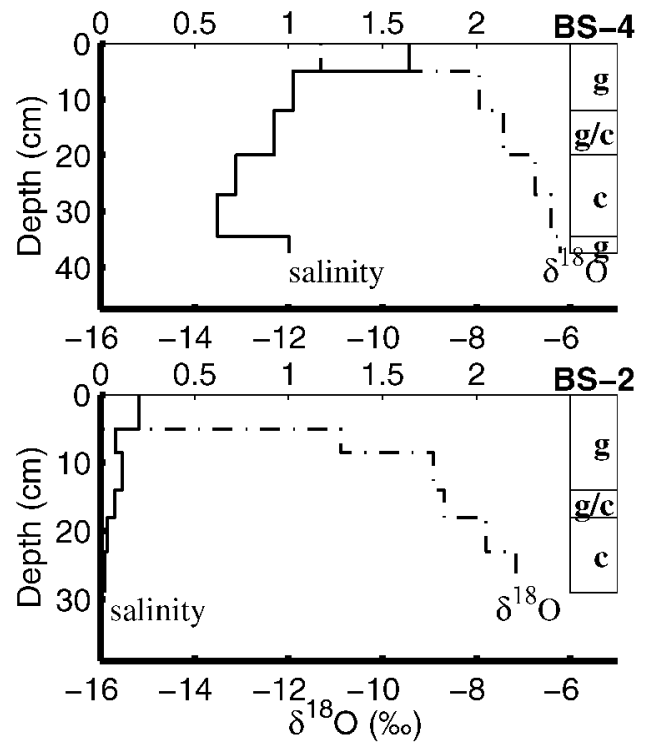

Fig. 3. Same as Figure 2, but for ice in the Bothnian Sea.

samples using a Schott handylab LFl (Schott Glas, Mainz, Germany) conductivity meter and UNESCO algorithms (Fofonoff and Millard, 1983) to an accuracy of 0.1 PSU.

\section{RESULTS AND DISGUSSION}

\subsection{Structure, stratigraphy and oxygen-isotopic characteristics}

A granular upper layer and a columnar lower layer are char-

Salinity (PSU)

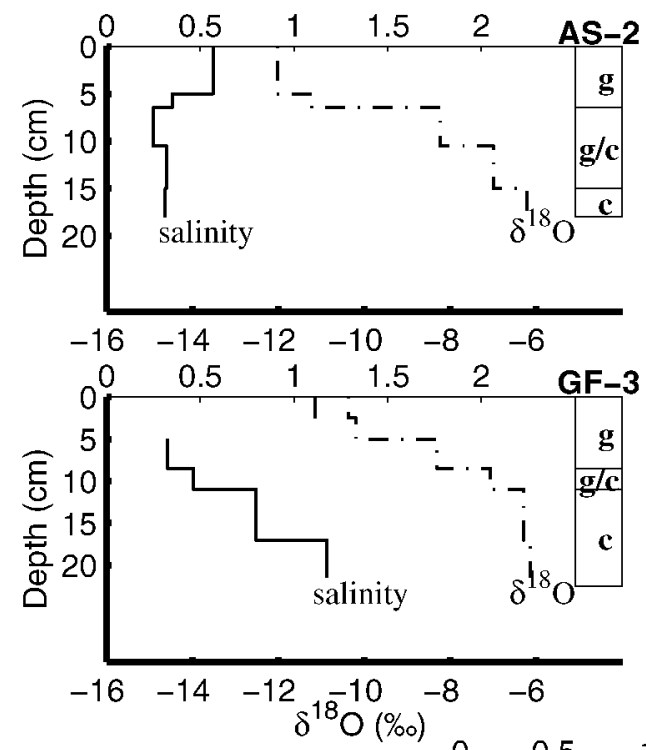

acteristic structural features of most of the cores. The granular ice layer often consisted of fine-grained layers (mm-sized crystals, denoted $\mathrm{g}$ in Figs 2-4) and a type of ice termed transition ice (Fig. 5, with cm-sized crystals, denoted g/c in Figs 24), which is an intermediate state resulting from oscillations between the granular- and columnar-ice growth modes (see Weeks and others, 1990). Figure 5 shows the structure of transition ice. The total ice thickness varied between 17 and $72 \mathrm{~cm}$, and the snow depth between 0 and $40 \mathrm{~cm}$, both showing a significant increase in thickness towards the north (Fig. 6b).
Salinity (PSU)

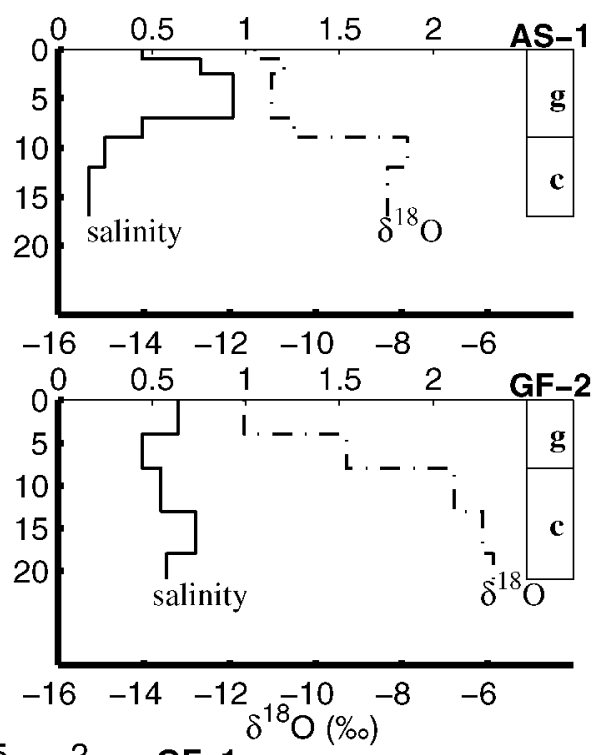

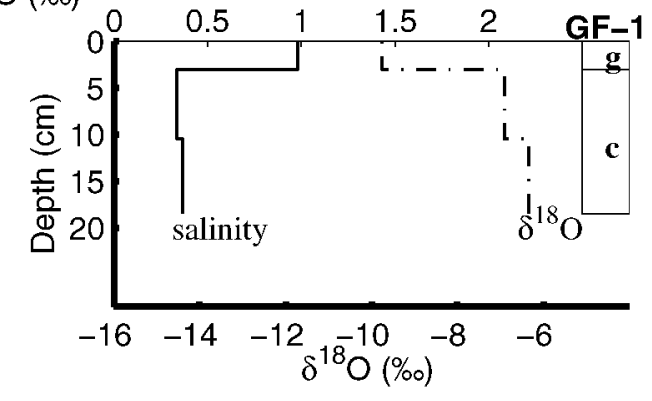

Fig. 4. Same as Figure 2, but for ice in the Archipelago Sea and the Gulf of Finland. 


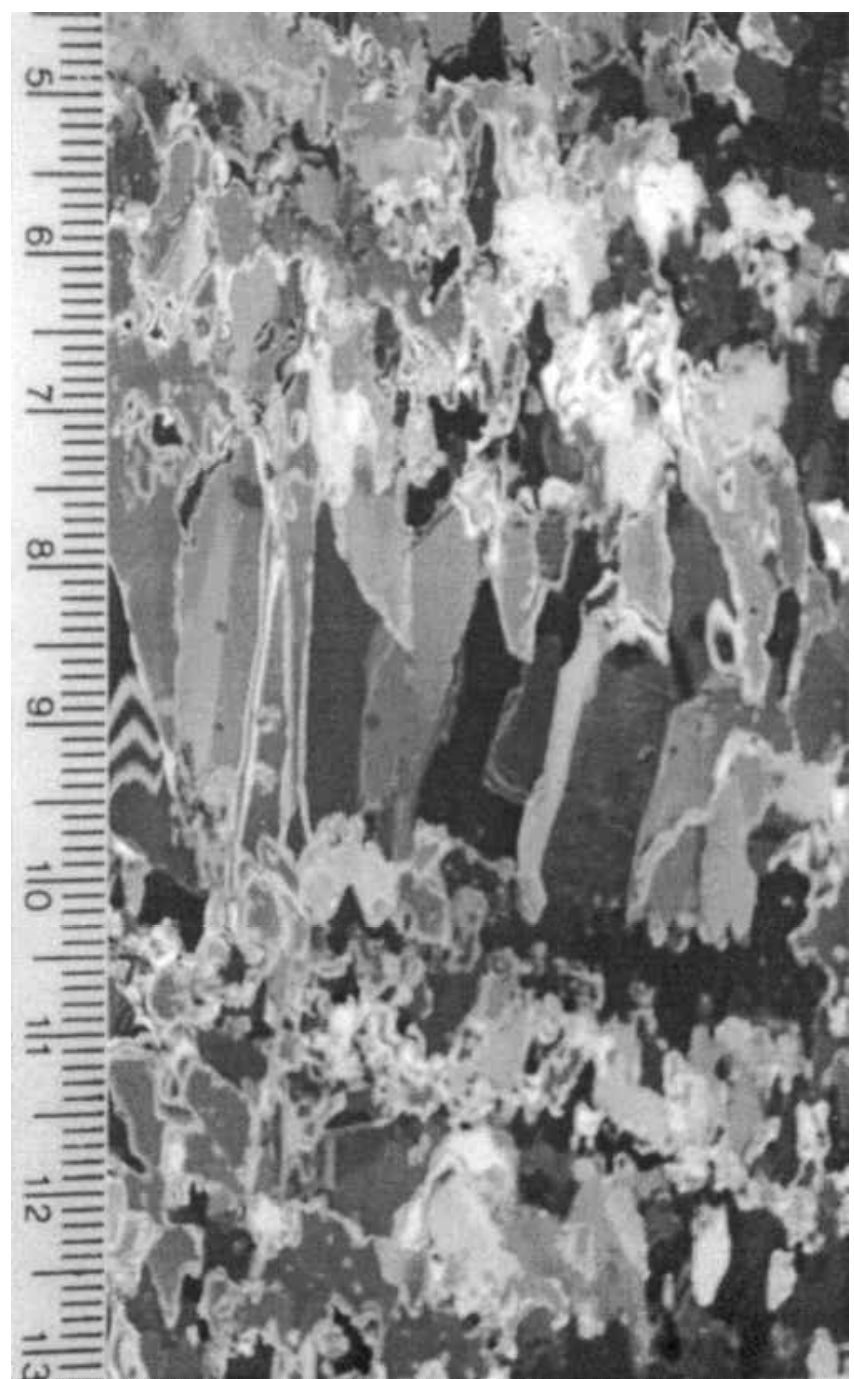

Fig. 5. A vertical thin section of transition ice, an intermediate granular-columnar ice type (see Eicken and Lange, 1989), photographed between crossed polarizers. Section is from depth 5-14 cm at site BS-3. The scale on the left is in centimeters.

There were large variations in the amount of the different ice types: columnar ice constituted $0-84 \%$ of the ice sheet, the average being $40.2 \%$, whereas granular layers ( $\mathrm{g}$ and $\mathrm{g} /$ c) constituted $16-100 \%$ (mean 59.8\%). Ice termed transition ice, defined as intermediate columnar granular ice by Eicken and Lange (1989), constituted on average $28.2 \%$ of the total ice thickness. The average values were computed according to the absolute method described in Jeffries (1997). The absolute method sums the total amount (in meters) of a particular ice type measured in each core and then divides that total by the total length of the cores (in meters) to give an absolute percentage for that ice type. All average values given hereafter are computed according to this method.

The relative contribution of different ice types showed no significant regional variability (Figs 2-4), the clearest exception being the significant contribution of transition ice in the Bothnian Bay (Fig. 2). The contribution of granular and columnar ice showed large variability, and no clear differences between the different basins were observed.

Major exceptions to the characteristic two-layer ice structure were observed at sites BS-4 and BB-1. At BS-4 and BB-1 the bottommost layer was composed of finegrained granular ice. This layer could be due to the generation of frazil ice in nearby open water, which had been driven below the fast ice at these sites. At BS- 4 the fast-ice edge was relatively close, and new ice formation was observed some days before the sampling, making this assumption plausible. Another possibility is refreezing of surface meltwaters when they come into contact with seawater at sub-zero temperatures. However, the under-ice water salinities did not indicate this as a plausible explanation, and the $\delta^{18} \mathrm{O}$ values were close to that of columnar ice, indicating a sea-water origin for these layers. This basal granular layer, however, did not contribute significantly to the total ice thickness at either BS-4 or BB-1, although it indicates that the generation of frazil ice in open leads at the fast-ice edge can also contribute to the sea-ice thickness.

At site BB-2, the whole core consisted of granular ice, finegrained on top, and large irregular crystals $(10-20 \mathrm{~mm})$ in the bottom layer, which could be regarded as transition ice $(\mathrm{g} / \mathrm{c}$ in Fig. 2). Similar thick layers of large irregular crystals were observed at sites BB-3 and BB-4 (see Fig. 2). For comparison, in the Antarctic, transition ice has been associated with nearby leads and a rough hydrodynamic regime (see Eicken and Lange, 1989, table 1 , defined as intermediate $\mathrm{c} / \mathrm{g}$ ). The $\delta^{18} \mathrm{O}$ values of transition-ice layers did not differ significantly from those in columnar-ice layers within individual sea-ice cores (paired $t$ test, $P=0.17$ ), indicating a sea-water origin for transition ice. On the other hand, the average $\delta^{18} \mathrm{O}$ for finegrained granular layers had significantly more negative values than transition or columnar ice in individual sea-ice cores (paired $t$ test, $P<0.05$ ). The salinity of fine-grained granular layers was significantly higher than in either columnar or transition ice (paired $t$ test, $P<0.05$ ), whereas transition ice and columnar ice had similar salinities (paired $t$ test, $P=$ 0.40 ) in individual sea-ice cores. Both the oxygen isotopic properties and salinity therefore indicate that the origin of transition ice (g/c ice in Figs 2-4) is from downward growth at the ice-water interface (see also Eicken and Lange, 1989). Possible mechanisms would be: (1) incorporation of frazil ice into the growing ice sheet; (2) enhanced growth rates due to changes in atmospheric conditions; and (3) changes in the hydrodynamic regime at the ice-water interface (Eicken and Lange, 1989). All mechanisms seem plausible, and further studies are needed to decipher the origin of this ice type in the Baltic Sea, since its contribution, especially in the Bothnian Bay, is very significant. However, the presence of transition ice could indicate that the fast-ice edge, with open leads, was close by at some stages of ice growth, and affected the hydrodynamic regime beneath the ice cover at those sites. A relatively small amount of transition ice (denoted $\mathrm{g} / \mathrm{c}$ in Figs 3 and 4) was found in the Bothnian Sea, Archipelago Sea and Gulf of Finland. This is probably because land-fast ice was found only in rather sheltered locations, in the archipelago, in skerries, bays or embayments where the growth conditions are more static.

A characteristic feature of the $\delta^{18} \mathrm{O}$ profiles is that the most negative values are encountered in the topmost granular layers. The $\delta^{18} \mathrm{O}$ values generally increase downwards in the ice, ranging from $-16.2 \%$ to $-5.9 \%$ o (Figs $2-4$ ). In snow, $\delta^{18} \mathrm{O}$ ranged between $-17.4 \%$ and $-8.3 \%$ (mean $-12.2 \%$ ); the range is somewhat smaller than for snow in the Weddell Sea (Eicken and others, 1994). There is a trend of increasing $\delta^{18} \mathrm{O}$ values in both columnar ice and snow going southwards (Fig. 6a), which correlates with increasing surface water salinities (e.g. Haapala and Alenius, 1994) and the north-south gradient in air temperature. Surface water 

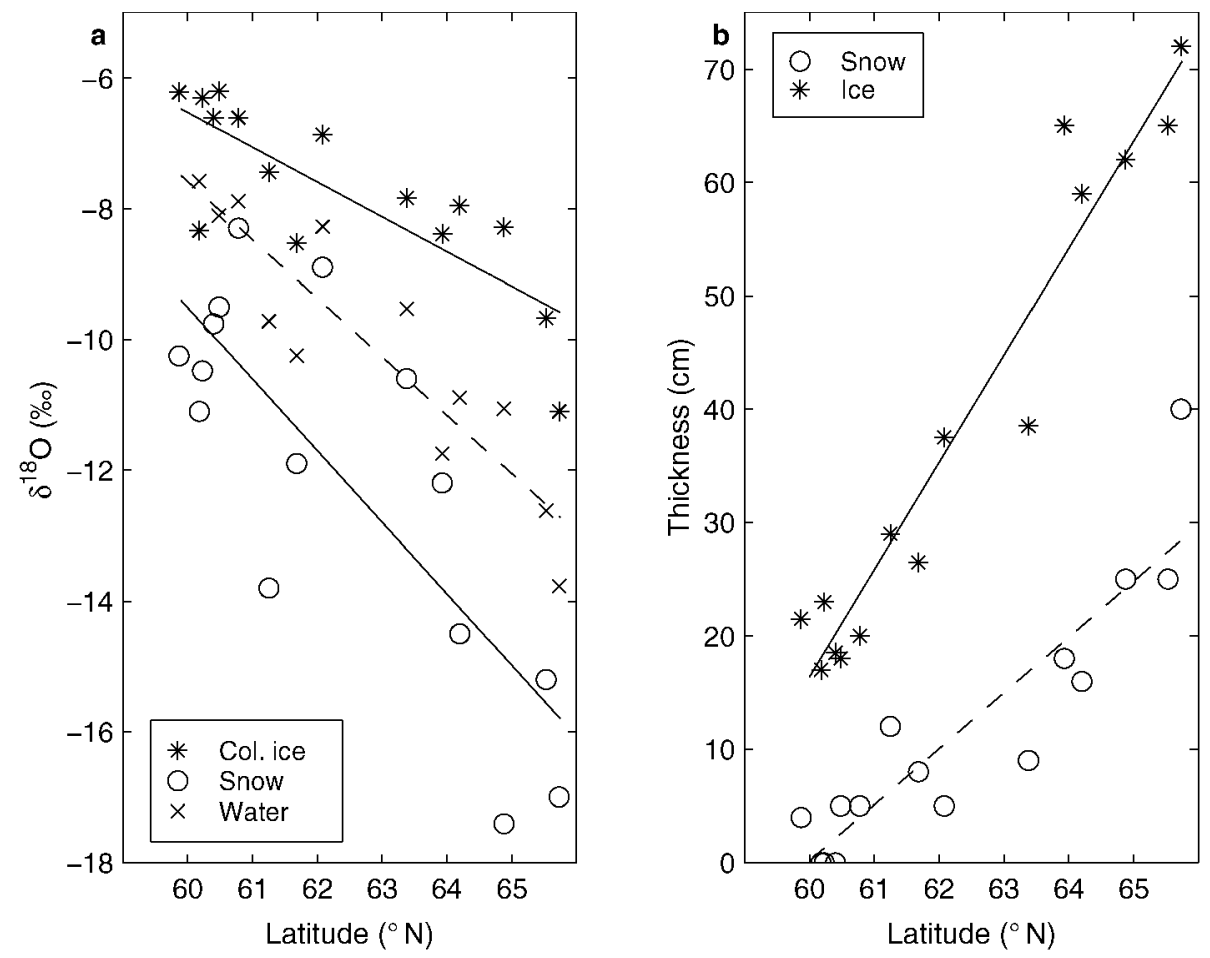

Fig. 6. (a) Relationship of $\delta^{18} \mathrm{O}$ in snow, under-ice water and columnar ice (average value for columnar ice in each core) with latitude; least-squares linear regression lines included, with $R^{2}=0.63,0.82$ and 0.65 for snow, water and columnar ice, respectively. (b) Relationship of ice and snow thickness with latitude; least-squares regression lines included, with $R^{2}=0.94$ and 0.83 for ice and snow thickness, respectively.

$\delta^{18} \mathrm{O}$ values follow a north-south trend similar to that for snow and columnar ice (Fig. 6a).

The least negative values in columnar layers are often encountered in the bottommost parts where the fraction- ation factor would be greatest due to slower growth rates when the ice gets thicker. On the other hand, the influence of under-ice spreading of riverine waters during the winter would tend to decrease the $\delta^{18} \mathrm{O}$ in surface waters; conse-

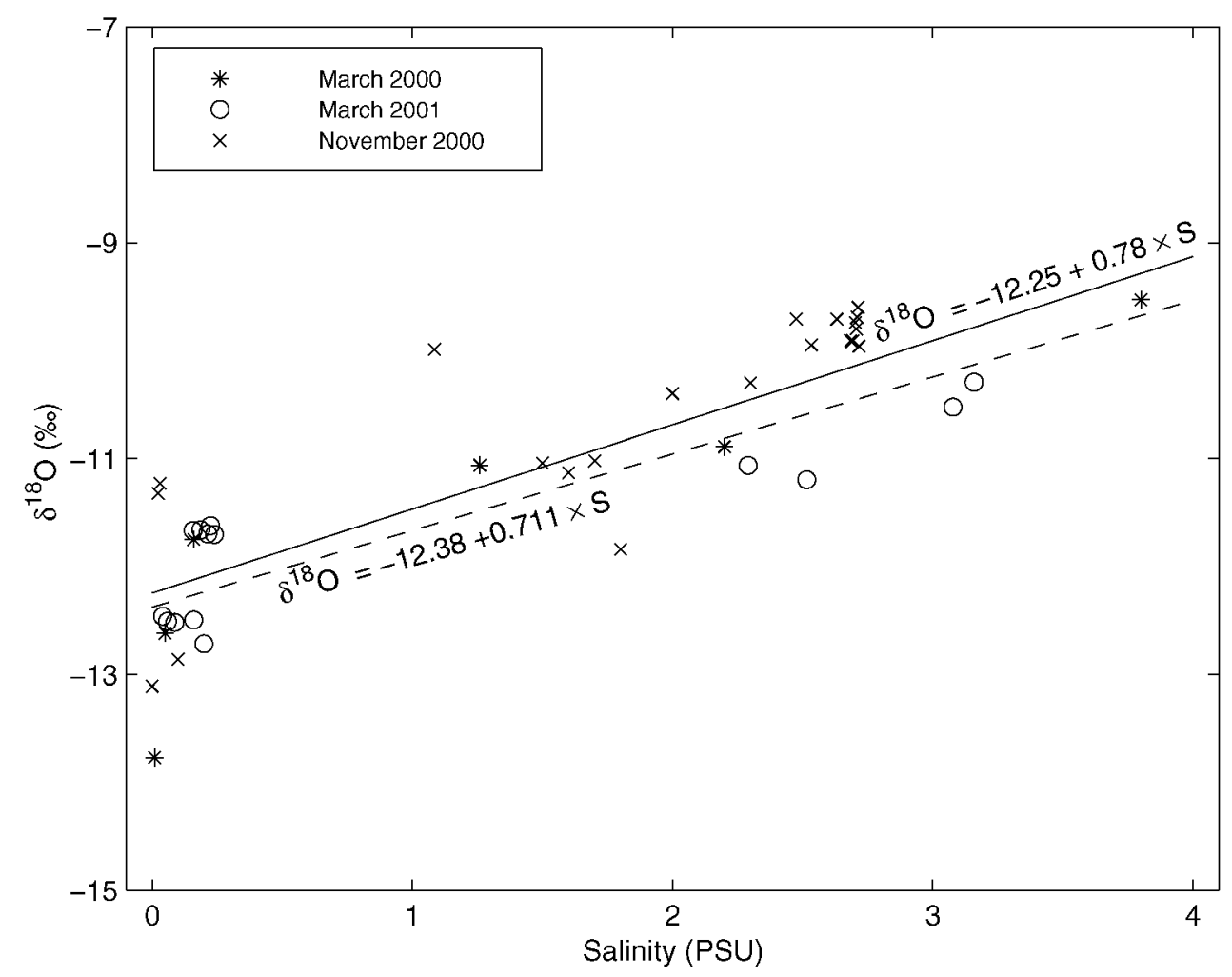

Fig. 7. Relationship of $\delta^{18} \mathrm{O}$ with salinity in surface waters in the Bothnian Bay sampled in March 2000 (under-ice water), November 2000 ( surface water during freeze-up) and March 2001 (under-ice water). Least-squares linear regression lines and equations included for whole dataset (solid line) and for under-ice samples (dashed line). 
quently $\delta^{18} \mathrm{O}$ in the columnar layers would decrease as the ice season progresses. Decreasing $\delta^{18} \mathrm{O}$ values toward the bottom of the ice cover, below the highly negative surface layers, are observed only at BB-2 and AS-1 (Figs 2 and 4); the most distinct decrease is at BB-2, where the crystal structure is very different to that at the other sites. Also the salinity profile at site BB-2 indicates an increasing fresh-water contribution during the ice season (Fig. 2). However, the ice salinity is also affected by lower growth rates, i.e. the lower the growth rate the more salt is expelled from the ice. The under-ice water salinity profile, however, showed no distinct fresh-water layer beneath the ice at BB-2.

\subsection{Identification of snow ice, frazil ice and transi- tion ice}

To differentiate between snow ice and frazil ice in sea ice requires stable-isotope data since the granular crystal texture of these ice types is very similar (Lange and others, 1990). Several different isotopic criteria were used by Jeffries and others (1997) to identify snow-ice layers; some of them have been adopted and modified to the Baltic Sea conditions. The use of average values of the whole study area in the Baltic Sea would tend to either over- or underestimate the contribution of snow and snow ice, since there is rather large spatial variability in the isotopic composition of both sea water (e.g. Punning and others, 1991) and precipitation in the study region (see IAEA, Isotope Hydrology Information System, the ISOHIS Database, accessible at: http://isohis.iaea.org). Conditions can differ significantly between different sampling sites, as seen in Figure 6a, so use of the properties of snow, ice and under-ice water at individual sites is more reliable than use of the average values over the whole study area, as in Antarctica by, among others, Jeffries and others (1997).

Many of our observation sites are potentially influenced by under-ice spreading of riverine waters, and $\delta^{18} \mathrm{O}$ values of the surface waters could then change or fluctuate during winter. However, under-ice salinity profiles indicated that none of the sampling sites had a distinct under-ice freshwater plume/layer during sampling. The northernmost sites (e.g. BB-6 and BB-5) have surface water salinities as low as $0.1 \mathrm{PSU}$ year-round, so $\delta^{18} \mathrm{O}$ values are not subject to drastic changes during winter. Observations at freeze-up and late winter (under-ice waters) in the Bothnian Bay indicate that surface water $\delta^{18} \mathrm{O}$ values in the study area fluctuate about $1 \%$ between the start of freezing and the end of winter (Fig. 7). Values tend to be higher at freeze-up time, and decrease slowly during winter. However, this occurs only in areas where the river input has an effect (see Alasaarela and Myllymaa, 1978). Assuming that the linear relationship between salinity and $\delta^{18} \mathrm{O}$ is a result of a two-component mixture, one component with high salinity (the water entering the Baltic Sea from the North Sea) and one with zero salinity (river inflow and precipitation), the $\delta^{18} \mathrm{O}$ value for the freshwater component in the study area in the Bothnian Bay is about $-12.3 \%$, estimated from the regression equations in Figure 7 (Fröhlich and others, 1988). The largest variability in $\delta^{18} \mathrm{O}$ values in Figure 7 is in waters with a salinity close to zero, i.e. in the vicinity of the river mouths. The large scatter is mainly attributed to differences in the location of the drainage basins. There are larger differences between different rivers than between seasonal values within the rivers in the study area, based on our limited dataset. Also Fröhlich and others (1988) noted that the water in the Baltic is not strictly a simple two-component mixture with two endmembers, the zero-salinity input and the high-salinity input from the North Sea, but that there are regional variations in the zero-salinity input.

One potential influence of river waters spreading on sea water could be to produce frazil ice, when more saline water below the freezing point of fresh water would cool down the river water and produce ice from double diffusion processes (see, e.g., McClimans and others, 1979). Evidence for such ice formation has yet to be presented for the Baltic Sea, and is probably constrained to the very mouth areas of rivers. Ice produced in this manner would have a lower isotopic signature than ice of ambient sea-water origin and could potentially be assumed to be snow ice. This would give a faulty estimate for the snow contribution. A prerequisite for this would then be that river water, close to or at freezing temperatures, would be present at the sampling sites in the early stages of freezing. As noted above, no evidence for river water as distinct layers below the ice was observed at the time of sampling or during a survey prior to freeze-up in 2000 , which also rules out the possibility of such ice formation in the early stages of ice growth. Earlier studies indicate that distinct river-water plumes form only under a prolonged ice cover (Alasaarela and Myllymaa, 1978). Frazil production due to double diffusion processes is probably present in close proximity to river mouths. However, observations of such ice-formation mechanisms are yet to be presented for the northern Baltic Sea.

The isotopic approach requires that the isotopic fractionation during ice formation is taken into account (Jeffries and others, 1997). Since we do not know the fractionation during ice formation, especially during snowice formation, we apply three different isotopic criteria to distinguish snow-ice layers from other ice types. The division between frazil ice and snow-ice layers by visual inspection is difficult, if not impossible. However, since the transition ice (denoted $\mathrm{g} / \mathrm{c}$ in Figs 2-4) was shown to have a sea-water origin (see section 3.1), those layers are not considered to have any snow contribution. Only layers denoted as $\mathrm{g}$ in Figures 2-4, i.e. fine-grained granular-ice layers, are considered to potentially have a snow contribution. Three isotopic criteria, described below, are used to determine ice layers as snow ice or frazil ice.

Criterion 1 assumes that any granular-ice layer (denoted $\mathrm{g}$ in Figures 2-4) with $\delta^{18} \mathrm{O}$ values less than $\delta_{\mathrm{sw}}^{18} \mathrm{O}$, the sea-water $\delta^{18} \mathrm{O}$ value at each site, has a snow contribution (cf. criterion 1, Jeffries and others, 1997). This criterion assumes no fractionation during snow-ice formation and can be regarded as a minimum estimate for the snow-ice contribution.

Griterion 2 takes into account that some fractionation will occur during snow-ice formation, and fine-grained granular layers with $\delta^{18} \mathrm{O}$ values below $\left(\delta_{\mathrm{sw}}^{18} \mathrm{O}+1.0\right) \%$ (cf. criterion 2, Jeffries and others, 1997). The observed value for isotopic fractionation during columnar-ice growth in the Gulf of Finland has been around 2\%o (Kawamura and others, 2001; derived as the difference between $\delta^{18} \mathrm{O}$ value of sea water and bottommost ice sections analyzed). The maximum fractionation during fresh-water ice formation, at zero growth rate, is assumed to be close to 3\%o (e.g. O’Neil, 1968; Lehmann and Siegenthaler, 1991). However, for a 4\% $\mathrm{NaCl}$ solution, Craig and Hom (1968) found a fractionation factor of 2.65\%. Furthermore, ice grown in natural conditions will not necessarily be formed in isotopic equilibrium, which depends on freezing rate and water mixing at the ice-water 
Table 2. Contribution of granular-ice (frazil ice and transition ice) and snow-ice layers (\%) to the total ice thickness averaged over all sites

\begin{tabular}{ccc}
\hline Criterion & Granularice & Snowice \\
\hline 1 & 35.9 & 23.9 \\
2 & 28.2 & 31.6 \\
3 & 28.2 & 31.6 \\
\hline
\end{tabular}

Note: Average values calculated according to the absolute method described in Jeffries (1997)

interface (Lehmann and Siegenthaler, 1991). For fractionation between sea water and sea ice, a value of $2.70 \%$ seems to apply during the slowest growth rates realized under natural conditions (Craig and Hom, 1968; Melling and Moore, 1995; Eicken, 1998). Since the fractionation processes during snow-ice formation have not been studied in great detail, we assume that fractionation is not as close to equilibrium as during columnar-ice formation, because snow-ice layers usually grow faster, and the fractionation will be less than that for columnar ice. Therefore we choose a value for fractionation that is between the observed value for Baltic Sea ice and zero fractionation. This represents an intermediate estimate for the contribution of snow ice.

Criterion 3 gives a plausible upper limit for the contribution of snow ice. Any granular-ice layer (denoted $g$ in Figs $2-4)$ with $\delta^{18} \mathrm{O}$ values less than $\delta_{\mathrm{c}}^{18} \mathrm{O}$, the average $\delta^{18} \mathrm{O}$ value for columnar ice at each site, has a snow contribution (cf. criterion 3, Jeffries and others, 1997). However, this assumption probably underestimates the amount of frazil ice, because isotopic fractionation during congelation (columnar-ice) growth is higher than during frazil-ice formation. Criterion 3 provides a plausible maximum estimate for the thickness contribution of snow-ice layers, and a minimum estimate for the amount of frazil ice. This assumption was also used by Kawamura and others (2001) to estimate the snow contribution in sea ice in the Gulf of Finland.

Of the above isotopic criteria those using values compared to the sea-water value at each site, i.e. criteria 1 and 2, would tend to underestimate, rather than overestimate, the amount of snow ice. This is because if the $\delta^{18} \mathrm{O}$ of sea water at the sites decreased during winter, as would be the case if the observational sites were influenced by runoff from land, one would use lower $\delta^{18} \mathrm{O}$ values of sea water as reference than would have been incorporated into the sea-ice cover earlier in the season.

The results for the thickness contribution of snow ice and granular ice using the different criteria described above are given in Table 2. Based on the above criteria, 23.3-31.6\% of the total ice thickness is composed of snow ice (i.e. a mixture of sea water and snow), and $31.6 \%$ can be regarded as the best (i.e. intermediate) estimate. The results using criteria 2 and 3 give identical results, because all transition ice layers are excluded from the identification process. Criterion 2 already incorporates all fine-grained layers, indicating that no frazil ice is present. In individual cores, the snow-ice thickness contribution ranged between $6 \%$ and $73 \%$ (criterion 2). The contribution of granular ice (frazil and transition ice) is of the same order as the contribution of snow ice, with transition ice having a substantial contribution in the Bothnian Bay, and frazil ice having a negligible contribution except for criterion $1(8 \%)$.

\subsection{Snow fractions}

Structural analyses alone do not accurately quantify the amount of snow ice and the amount of snow incorporated into the ice sheet. For such information, $\delta^{18} \mathrm{O}$ data have been used to distinguish between different ice types or to determine the contribution of snow to the sea-ice cover in Antarctic regions (e.g. Gow and Epstein, 1972; Lange and others, 1990; Eicken and others, 1994; Jeffries and others, 1994; Jeffries, 1997; Kawamura and others, 1997). In order to quantitatively estimate the fraction of snow in granularice layers and sea-ice cores, they all assumed that only granular-ice layers had a contribution from snow. A simplified model developed by Jeffries and others (1994) from the original model by Lange and others (1990) is:

$$
\begin{array}{r}
f_{\mathrm{s}}+f_{\mathrm{sw}}=1 \\
f_{\mathrm{s}} \delta_{\mathrm{s}}+f_{\mathrm{sw}} \delta_{\mathrm{sw}}=\delta,
\end{array}
$$

where $f_{\mathrm{s}}$ is the snow fraction (by mass) and $f_{\mathrm{sw}}$ the seawater fraction (by mass) of the granular-ice section in question and $\delta_{\mathrm{s}}$ is the $\delta^{18} \mathrm{O}$ value for snow at each site $(-8.3$ to $-17.4 \%$ (Fig. 6)). For the $\delta_{\mathrm{sw}}$ value, we use the sea-water value at each site, with 1 added $\left(\delta_{\mathrm{sw}}^{18} \mathrm{O}+1.0\right)$, which allows for some isotopic fractionation during the formation of snow ice (see Jeffries and others, 1997), and $\delta$ is the $\delta^{18} \mathrm{O}$ value for the granular-ice section for which the snow fraction is being determined.

The total snow fraction (by mass) of the entire ice thickness in each core, $F_{\mathrm{m}}$, was obtained according to:

$$
F_{\mathrm{m}}=\sum\left(f_{\mathrm{s}} \frac{h_{\mathrm{i}}}{h_{\mathrm{tot}}}\right),
$$

where $f_{\mathrm{s}}$ is the snow fraction and $h_{\mathrm{i}}$ is the thickness of individual snow-ice layers in the core for which $F_{\mathrm{m}}$ is being determined. $h_{\text {tot }}$ is the total length of the ice core. Several snow-ice layers were encountered in the cores, because the topmost fine-grained layer was usually divided into several sections along stratigraphic boundaries.

Snow-fraction $\left(F_{\mathrm{m}}\right)$ values resulting from applying Equations $(1-3)$ to granular-ice layers, which have been identified as snow-ice layers using criteria 1 and 2 (see section 3.2), are shown in Table 3 . On average, $20.7 \%$ of the ice in the study region consisted of snow using the intermediate criterion. Applying the above equation to snow-ice layers identified by criterion 3 gives the same values as criterion 2. The minimum estimate (criterion 1) gives an average snow fraction of $18.3 \%$.

$f_{\mathrm{s}}$ values for individual snow-ice layers ranged from $3 \%$ to $213 \%$, with an average of $54 \%$ for those layers with values $<100 \%$. Those above $100 \%$ were corrected to a value of $100 \%$ when the $F_{\mathrm{m}}$ values were computed, even though a value of $100 \%$ or more indicates that the whole layer consisted of snow only, which is not usually plausible unless superimposed ice is formed from melting snow. Only at one site, AS-1, is this a plausible explanation for $f_{\mathrm{s}}$ values $>100 \%$. In the rest of the cases, the $\delta_{\mathrm{s}}$ value at that site was higher than the $\delta^{18} \mathrm{O}$ values for the corresponding granularice layers. This implies that temporal variability in $\delta^{18} \mathrm{O}$ values for the snow should be taken into account in order to improve the estimate for the $\delta_{\mathrm{s}}$ value for snow included in the ice cover. However, using the average $\delta^{18} \mathrm{O}$ values for snow at all sites, or for each basin, in Equations (1) and (2), instead of the individual value for each site, does not 
Table 3. The snow fraction, $F_{\mathrm{m}}(\%)$, at the different sites derived with the isotopic mass-balance model (Equations (1) and (2) ) applied to snow-ice layers as identified by criteria 1 and 2 (see text)

\begin{tabular}{lrr}
\hline Site & & $F_{\mathrm{m}}$ \\
& Criterion 1 & Criterion 2 \\
\hline BB-6 & 27.0 & \\
BB-5 & 16.9 & 27.0 \\
BB-4 & 8.3 & 16.9 \\
BB-3 & 5.6 & 8.3 \\
BB-2 & 4.6 & 5.6 \\
BB-1 & 40.0 & 4.9 \\
BS-4 & 13.3 & 40.0 \\
BS-3 & 20.3 & 22.9 \\
BS-2 & 22.4 & 24.2 \\
BS-1 & 26.1 & 23.1 \\
AS-2 & 46.6 & 45.7 \\
AS-1 & 42.3 & 46.6 \\
GF-3 & 14.4 & 42.3 \\
GF-2 & 24.2 & 17.4 \\
GF-1 & 8.4 & 24.2 \\
Mean & 18.3 & 8.4 \\
& & 20.7 \\
\hline
\end{tabular}

Note: Mean values calculated according to the absolute method described in Jeffries (1997).

improve or change the results very much. This indicates that the temporal variability of the snow properties is the most important parameter to consider when improving the estimates presented here. There can be large seasonal fluctuations in the isotopic signature of precipitation in the Baltic Sea area (Punning and others, 1991). However, there are virtually no data on the $\delta^{18} \mathrm{O}$ of snow or precipitation in the Gulf of Bothnia or along the coasts of Finland (see, e.g., Fröhlich and others, 1988; Punning and others, 1991), which regrettably undermines an effort to present more exact figures here. Therefore our maximum estimate (20.7\%) should be considered as a plausible upper limit for the snow contribution to the sea-ice mass balance in the study region.

Applying the methods used in this study to the data presented by Kawamura and others (2001), the estimates for the snow fractions in the Gulf of Finland in winter 1999 decrease to $20 \%$ at maximum (compared to $26 \%$ in Kawamura and others (2001)). The method used by Kawamura and others (2001), described as criterion 3 in this study, tends to overestimate the snow contribution in the snow-ice layers (Jeffries and others, 1997). Furthermore Kawamura and others (2001) used a $\delta_{\mathrm{sw}}$ value assuming that the fractionation during snowice formation is as high as during columnar-ice growth, which is probably not the case since snow-ice growth is usually faster than growth at the ice--water interface. Therefore the fractionation is not as close to equilibrium during snow-ice formation.

The temporal variability of the snow properties $\left(\delta^{18} \mathrm{O}\right.$ and density) should also be better taken into account, and in the Baltic Sea area there is a need for more systematic measurements of the isotopic composition of sea water, river inflow and precipitation (including snow) (see Fröhlich and others, 1988), especially in the Gulf of Bothnia where data are virtually non-existent. These observations would be valuable in sea-ice studies, as well as in more detailed studies of the water balance in the region (Fröhlich and others, 1988). There is also a need for more detailed information about isotopic fractionation during consolidation of mixtures of snow and sea water, in order to be able to present more accurate estimates of the snow contribution to sea-ice mass balance, not only in the Baltic Sea area, but also in areas where isotopic methods have been widely used (e.g. in Antarctic sea ice).

\section{CONGLUSIONS}

The $\delta^{18} \mathrm{O}$ profiles of sea-ice cores typically follow the structural properties, with the most negative values in the granular surface layers, which is typical of both Antarctic sea ice (e.g. Lange and others, 1990; Jeffries and others, 1994) and land-fast sea ice in the Gulf of Finland (Kawamura and others, 2001).

Even the minimum estimate for the snow-ice contribution to the total ice thickness is significant $(23.9 \%)$; the intermediate estimate of $31.6 \%$ should be considered an upper estimate. The results are in agreement with observations from land-fast sea ice in the Gulf of Finland (Kawamura and others, 2001), with values of $14-42 \%$. Our observations are in reasonable agreement with Palosuo (1963), who studied the snow-ice thickness using a gauge-stick; he observed values up to about $50 \%$ at sites along the Finnish coast. There was, however, large interannual variability in the contribution of snow ice (see Palosuo, 1963). Values similar to or somewhat lower than those reported here for the contribution of snow ice have been reported by Jeffries and others (1997), which are among the highest values reported from Antarctic sea ice. Generally the values reported from Antarctica are somewhat lower.

The contribution of frazil ice is negligible, at maximum only $8 \%$ (criterion 1 ), which indicates that dynamic ice formation is not important in the coastal regions in the northern Baltic Sea. However, an ice type termed transition ice, with large irregular crystals up to several centimeters in size, contributed significantly, with an average contribution of $28 \%$ in the whole study area and a significant contribution in the Bothnian Bay. The isotopic properties and salinities indicate that this ice type originates from growth at the ice-water interface; however, the exact formation processes for this ice type need further study. The processes proposed by Eicken and Lange (1989) for Antarctic waters all seem applicable to the Baltic Sea as well.

The estimated snow fraction in the ice cores, on average $18.3-20.7 \%$ (by mass), is significant when compared to observations in other regions. However, both estimates are slightly high, as some snow-ice layers contributed $100 \%$ of snow, which is not plausible (except in cases with superimposed-ice formation). In the seasonally ice-covered Sea of Okhotsk, the snow fraction was estimated to be about 8\% (Ukita and others, 2000). The maximum reported snow fraction in Antarctic sea ice is 14-16\% (Jeffries and others, 1997). Whereas Kawamura and others (2001) reported values of $2-26 \%$ during the ice season at one site in the Gulf of Finland, the highest values, from the late season, compare favorably with our observations. The methods used by Kawamura and others (2001) provided a plausible upper limit for the snow contribution, and their maximum estimate decreases to $20 \%$ using the methods applied in this study.

In order to improve the estimate of the snow fraction, the temporal variability in isotopic properties of snow should be better taken into account. This is revealed by the fact that $f_{\mathrm{s}}$ values for some individual snow-ice layers exceeded $100 \%$, which indicates that the isotopic properties of the snow 
incorporated into the ice cover were different than for the sampled snow. However, it was beyond the scope of this study to make systematic long-term observations of the isotopic composition of precipitation, even though earlier observations would have been useful for the purpose of this study. We also infer that other workers conducting similar studies should critically check their results, since the snow collected does not necessarily represent the snow that has been incorporated into the sea-ice cover, and could therefore alter the results obtained.

In summary, we have shown that snow contributes significantly to the mass balance of land-fast sea ice in the entire northern Baltic Sea. On average, the snow-ice thickness is about one-third to one-quarter of the total ice thickness, and the snow fraction is about one-fifth of the total ice mass. This is higher than generally reported for Antarctic sea ice and the seasonally ice-covered Sea of Okhotsk, and confirms that the findings by Kawamura and others (2001) seem to be applicable to the land-fast sea-ice cover in the entire northern Baltic Sea. The question arises as to the applicability of our results to the Baltic Sea as a whole, since a large portion of the ice cover is composed of pack ice (e.g. in the Bothnian Bay about twothirds by area). Therefore the logical next step would be to study the pack ice in more detail. Also the use of long-term studies, on seasonal or longer time-scales, would shed more light on the interannual and seasonal variability of these processes and improve the estimates presented here.

\section{AGKNOWLEDGEMENTS}

The authors would like to thankJ. Ehn and K. Meiners for help in the field. A. Blanco, K. Kanto, E. Kärkäs and J. Uusikivi assisted in the cold rooms. J. Vainio and P. Eriksson provided the ice chart. H. Eicken, M. O. Jeffries and J. G. Moore are thanked for constructive comments on earlier versions of the manuscript. The comments of T. Gow and and anonymous reviewer as well as the help of M. Lange (Scientific Editor) led to improvements in the manuscript. Funding for this study was provided by the Academy of Finland, through the "Graduate School for Snow and Ice Research" and the project "Coastal sea ice and oceanography in the Baltic Sea in winter".

\section{REFERENGES}

Alasaarela, E. and U. Myllymaa. 1978. Investigations into the dispersal of river and waste waters in the northeastern part of the Bothnian Bay in 1975-1977. Finn. Mar. Res. 244, 173-182.

Craig, H. and B. Hom. 1968. Relationships of deuterium, ${ }^{18} \mathrm{O}$, and chlorinity in the formation of sea ice. AGU Trans., 49 (1), 216-217.

Eicken, H. 1998. Deriving modes and rates of ice growth in the Weddell Sea from microstructural, salinity and stable-isotope data. In Jeffries, M. O., ed. Antarctic sea ice: physical processes, interactions and variability. Washington, DC, American Geophysical Union, 89-122. (Antarctic Research Series 74.)

Eicken, H. and M. A. Lange. 1989. Development and properties of sea ice in the coastal regime of the southeastern Weddell Sea. 7. Geophys. Res., 94(C6), 8193-8206.

Eicken, H., M. A. Lange, H.-W. Hubberten and P. Wadhams. 1994. Characteristics and distribution patterns of snow and meteoric ice in the Weddell Sea and their contribution to the mass balance of sea ice. Ann. Geophysicae, 12(1), 80-93.

Eicken, H., H. R. Krouse, D. Kadko and D. K. Perovich. 2002. Tracer studies of pathways and rates of meltwater transport through Arctic summer sea ice. 7. Geophys. Res., 107(C10). (10.1029/2000JC000583)

Fofonoff, N. P. and R. C. Millard, Jr. 1983. Algorithms for computation of fundamental properties of seawater. UNESCO Tech. Pap. Mar. Sci. 44.

Fransson, L., B. Håkansson, A. Omstedt and L. Stehn. 1990. Sea ice properties studied from the icebreaker Tor duxing BEPERS-88. Norrköping, Sveriges Meteorologiska och Hydrologiska Institut. (SMHI Report Oceanography 10.)

Fritsen, C. H., V. I. Lytle, S. F. Ackley and C.W. Sullivan. 1994. Autumn bloom of Antarctic pack-ice algae. Science, 266(5186), 782-784.

Fröhlich, K., J. Grabczak and K. Rozanski. 1988. Deuterium and oxygen-18 in the Baltic Sea. Chemical Geol., 72, 77-82.

Gow, A. J. and S. Epstein. 1972. On the use of stable isotopes to trace the origins of ice in a floating ice tongue. F. Geophys. Res., 77(33), 6552-6557.

Haapala, J. and P. Alenius. 1994. Temperature and salinity statistics for the northern Baltic Sea, 1961-69. Finn. Mar. Res. 262, 51-121.

Haapala, J. and M. Leppäranta. 1996. Simulating the Baltic Sea ice season with a coupled ice-ocean model. Tellus, 48A(5), 622-643.

Haapala, J. and M. Leppäranta. 1997. The Baltic Sea ice season in changing climate. Boreal Environ. Res., 2(1), 93-108.

Haas, C., D. N. Thomas and J. Bareiss. 2001. Surface properties and processes of perennial Antarctic sea ice in summer. 7. Glaciol., 47(159), 613-625.

Jeffries, M. O. 1997. Describing the composition of sea-ice cores and the development of the Antarctic sea-ice cover. Antarct. F. U.S., 32(5), Review 1997, 55-56.

Jeffries, M. O., R. A. Shaw, K. Morris, A. L. Veazey and H. R. Krouse. 1994. Crystal structure, stable isotopes $\left(\delta^{18} \mathrm{O}\right)$, and development of sea ice in the Ross, Amundsen, and Bellingshausen seas, Antarctica. 7. Geophys. Res., 99(C1), 985-995.

Jeffries, M. O., A. P. Worby, K. Morris and W. F. Weeks. 1997. Seasonalvariations in the properties and structural composition of sea ice and snow cover in the Bellingshausen and Amundsen Seas, Antarctica. F. Glaciol., 43(143), 138-151.

Kawamura, T., K. I. Ohshima, T. Takizawa and S. Ushio. 1997. Physical, structural and isotopic characteristics and growth processes of fast sea ice in Lützow-Holm Bay, Antarctica. 7. Geophys. Res., 102(C2), 3345-3355

Kawamura, T. and 9 others. 2001. Time-series observations of the structure and properties of brackish ice in the Gulf of Finland. Ann. Glaciol., 33, 1-4.

Lange, M. A., P. Schlosser, S. F. Ackley, P. Wadhams and G. S. Dieckmann. 1990. ${ }^{18} \mathrm{O}$ concentrations in sea ice of the Weddell Sea, Antarctica. 7 . Glaciol., 36(124), 315-323.

Lehmann, M. and U. Siegenthaler. 1991. Equilibrium oxygen- and hydrogenisotope fractionation between ice and water. 7. Glaciol., 37(125), 23-26.

Leppäranta, M. 1981. On the structure and mechanics of pack ice in the Bothnian Bay. Finn. Mar. Res. 248,3-86.

Maksym, T. and M. O. Jeffries. 2000. A one-dimensional percolation model of flooding and snow-ice formation on Antarctica sea ice. f. Geophys. Res., 105(C11), 26,313-26,331.

McGlimans, T. A., J. E. Steen and J. H. Kjeldgaard. 1979. Ice formation in fresh water cooled by a more saline underflow. In 4th IAHR Symposium on Ice Problems, 7-9 August 1978, Lulea, Sweden. Vol. 2. International Association for Hydraulic Research. Committee on Ice Problems, 20-29.

Melling, H. and R. M. Moore. 1995. Modification of halocline source waters during freezing on the Beaufort Sea shelf: evidence from oxygen isotopes and dissolved nutrients. Continental Shelf Res., 15(1), 89-113.

Omstedt, A. 1985. An investigation of the crystal structure of sea ice in the Bothnian Bay. Norrköping, Sveriges Meteorologiska och Hydrologiska Institut. (SMHI RHO 40.)

O’Neil, J. R. 1968. Hydrogen and oxygen isotope fractionation between ice and water. 7. Phys. Chem., 72(10), 3683-3684.

Palosuo, E. 1961. Crystal structure of brackish and fresh-water ice. International Association of Scientific Hydrology Publication 54 (General Assembly of Helsinki 1960 - Snow and Ice), 9-14.

Palosuo, E. 1963. The Gulf of Bothnia in winter. II. Freezing and ice forms. Merentutkismuslaitoksen Fulkaisu/Havsforskningsinst. Skr. 209, 42-64.

Punning, J.-M., R. Vaikmäe and S. Mäekivi. 1991. Oxygen-18 variations in the Baltic Sea. Nuclear Geophys., 5(4), 529-539.

Seinä, A. and J. Peltola. 1991. Duration of the ice season and statistics of fast ice thickness along the Finnish coast 1961-1990. Finn. Mar. Res. 258,3-46.

Ukita, J., T. Kawamura, N. Tanaka, T. Toyota and M. Wakatsuchi. 2000. Physical and stable isotopic properties and growth processes of sea ice collected in the southern Sea of Okhotsk. F. Geophys. Res., 105(C9), 22,083-22,093

Weeks, W. F., A. J. Gow, P. Kosloff and S. Digby-Argus. 1990. The internal structure, composition and properties of brackish ice from the Bay of Bothnia. CRREL Monogr. 90-1, 5-15. 